\title{
Implementasi Algoritma AES Untuk Pengamanan Login Dan Data Customer Pada E-Commerce Berbasis Web
}

\author{
Laila Mustika \\ Program Studi Teknik Informatika, STMIK Budi Darma, Medan, Indonesia \\ Email: ${ }^{1}$ lailamustika42@gmail.com
}

Submitted 13-01-2020; Accepted 09-02-2020; Published 15-02-2020

\begin{abstract}
Abstrak
Pada bidang E-Commerce pengamanan website sangat diperlukan mengingat banyak cyber crime yang mengincar website komersial. Beberapa yang perlu diamankan adalah login, karena login bersifat rahasia dan penting untuk mengakses sebuah website yang memiliki hak akses akun. Selain itu data customer juga perlu diamankan data-datanya dari orang yang tidak memiliki hak akses, untuk mencegah dan menghindari perubahan dan perusakan data. Jika data customer diketahui oleh pihak yang tidak memiliki hak akses, data tersebut bisa disalahgunakan dan bisa menimbulkan kasus penipuan. Maka dari itu diperlukannya sebuah algoritma untuk mengamankan website tersebut. Algoritma yang dapat dipakai untuk mengamankan sebuah website salah satunya adalah kriptografi. Dalam kriptografi pesan atau data penting dan rahasia di enkripsi dan deskripsi menggunakan sebuah kunci simetrik atau kunci asimetrik yang hanya diketahui oleh pihak yang berwenang. Algoritma kriptografi terdapat beberapa metode yang dapat diterapkan ke dalamnya, salah satunya adalah metode AES (Advanced Encryption Standard).Algoritma AES memiliki panjang blok 128 bit dan mampu mendukung panjang kunci 128, 192, dan 256bit, selain itu algoritma AES lebih murah dalam biaya dan lebih mudah diimplementasikan pada memori berukuran kecil.Hasil dari penerapan Algoritma AES menjadikan website lebih aman dan diharapkan customer bertambah dengan meningkatnya keamanan websitedan kepercayaan customer.
\end{abstract}

Kata Kunci: Algoritma AES, Pengamanan Login, Data Customer, E-Commerce.

\begin{abstract}
In the field of E-Commerce website security is very necessary considering that many cyber crimes target commercial websites. Some that need to be secured are logins, because logins are confidential and important to access a website that has account access rights. In addition, customer data also needs to be secured data from people who do not have access rights, to prevent and avoid data changes and destruction. If customer data is known by parties who do not have access rights, the data can be misused and can lead to fraud cases. Therefore an algorithm is needed to secure the website. One of the algorithms that can be used to secure a website is cryptography. In cryptography messages or important and confidential data are encrypted and described using a symmetric key or asymmetric key that is only known by the authorities. There are several methods of cryptographic algorithm that can be applied to it, one of them is the AES (Advanced Encryption Standard) method. AES algorithm has a block length of 128 bits and is able to support key lengths of 128, 192, and 256bit, besides that AES algorithm is cheaper in cost and more easily implemented in small memory. The results of the application of the AES Algorithm make the website safer and it is hoped that customers will increase with increased website security and customer trust
\end{abstract}

Keywords: AES Algorithm, Login Security, Customer Data, E-Commerce.

\section{PENDAHULUAN}

Ilmu teknologi yang semakin berkembang dan diperbaharui secara bertahap khususnya dalam bidang komputer, sangat membantu manusia dalam mendapatkan informasi. Perkembangan ilmu teknologi bidang komputer dapat dilihat dari semakin canggihnya perangkat keras komputer maupun perangkat lunak. Perkembangan itu juga berpengaruh terhadap keamanan penggunaan komputer maupun layanan publik yang semakin meningkatkan keamanan dalam pengambilan informasi.

Ilmu teknologi juga sudah mulai diterapkan dalam bidang penjualan dan pemasaran produk secara online sehingga mempermudah untuk memasarkan produk ke publik. Penjualan dan pemasaran produk barang dan jasa menggunakan jaringan komunikasi untuk melakukan proses bisnis disebut $e$-commerce. Dalam bidang e-commerce juga diperlukan sebuah pengamanan login, pemilik akun harus melakukan login terlebih dahulu agar dapat mengakses website e-commerce. Namun proses login dapat disabotase oleh pihak ketiga yang tidak memiliki hak akses (account). Mereka melakukan sabotase terhadap website dengan membobol account website melalui login account. Hal ini sangat merugikan pemilik website ecommerce, karena pihak ketiga yang tidak memiliki hak akses tersebut bisa merusak data atau mengubah data yang dapat berakibat fatal.

Selain pengamanan login, data customer juga diperlukan sebuah pengamanan agar data rahasia yang penting, tidak diketahui oleh pihak yang tidak memiliki hak akses. Data customer berupa data-data penting seperti info E-mail, No Hp, dan Alamat yang rawan untuk disalahgunakan oleh pihak yang tidak bertanggung jawab. Jika sebuah data customer disalahgunakan maka besar kemungkinan terjadi penipuan yang merugikan customer. Data customer dirasa sangat perlu diamankan karena bersangkutan dengan kepercayaan customer terhadap website e-commerce yang dikunjunginya. Karena kepercayaan customer sangat diperlukan untuk meningkatkan pemasaran dalam e-commerce. Jika customer sudah percaya terhadap sebuah website e-commerce yang akan menjaga data-data mereka dengan baik, maka mereka akan nyaman dan berlangganan berbelanja. Jika kepercayaan customer hilang, sehingga pemilik website e-commerce juga turut dirugikan karena akan kehilangan customer dan pelanggannya. Oleh karena itu dibutuhkan pengamanan dalam website e-commerce dalam hal ini pengamanan login dan data customer, agar konsumen tidak merasa kecewa atau terjadinya penipuan. Kriptografi sangat cocok diterapkan untuk pengamanan dalam bidang e-commerce, karena dapat mengamankan suatu pesan 
maupun data lainnya yang bersifat rahasia sehingga isi asli dari pesan maupun data tersebut tidak diketahui pihak lain yang bukan pemilik aslinya.

Dalam kriptografi terdapat banyak algoritma, salah satunya adalah algoritma AES (Advanced Encryption Standard). Algoritma AES memiliki panjang blok 128 bit dan mampu mendukung panjang kunci 128, 192, dan 256 bit. Algoritma AES digunakan untuk mengenkripsi dan deskripsi informasi, yang menggunakan proses yang berulang yang disebut ronde. Selain itu AES lebih efisien dari segi biaya dan lebih mudah diimplementasikan pada memori berukuran kecil[1].

Pada penelitian terdahulu yang dilakukan oleh Syaiful Anwar dalam Implementasi Pengamanan Data dan Informasi dengan Metode Steganografi LSB dan Algoritma Kriptografi AES. Pengujian yang dilakukan pada penelitian ini berupa dengan melihat aspek recovery dan aspek imperceptibility pada metode modifikasi LSB. Penelitian ini menekankan bahwa kombinasi dari modifikasi LSB dan algoritma AES dapat digunakan dalam meningkatkan keamanan data[2].

Lalu pada penelitian terdahulu terhadap e-commerce yang dilakukan oleh Shabur Miftah Maulana, dalam Implementasi E-Commerce Sebagai Media Penjualan Online (Studi Kasus Pada Toko Pastbrik Kota Malang). Mengimplementasikan website e-commerce yang berfungsi sebagai media promosi dan penjualan elektronik. Serta mengetahui kendala yang dihadapi dalam mengimplementasikan website e-commerce[3].

\section{METODE PENELITIAN}

\subsection{Kriptografi}

Kriptografi berasal dari bahasa Yunani, crypto dan graphia.Crypto berarti secret (rahasia) dan graphia berarti writing (tulisan). Menurut terminologinya, kriptografi merupakan ilmu dan seni untuk menjaga keamanan pesan ketika pesan dikirim dari suatu tempat ke tempat lain[2]. Sehingga dapat disimpulkan bahwa kriptografi adalah ilmu yang mempelajari keamanan pesan yang akan dikirim ke suatu tempat.

\subsection{Algoritma AES}

Algoritma AES merupakan sistem penyandian blok yang bersifat non-feistel karena AES menggunakan komponen yang selalu memiliki invers dengan panjang blok 128 bit. Penyandian AES menggunakan proses yang berulang yang disebut dengan ronde. Jumlah ronde yang digunakan oleh AES tergantung dengan panjang kunci yang digunakan. Setiap ronde membutuhkan kunci ronde dan masukan dari ronde berikutnya, kunci ronde dibangkitkan berdasarkan kunci yang diberikan[1]. Algoritma AES terdiri dari enkripsi dan deskripsi, Enkripsi AES adalah transformasi terhadap state secara berulang dalan beberapa ronde. State yang menjadi keluaran ronde k menjadi masukan untuk ronde ke k+1. Secara ringkas algoritma deskripsi AES merupakan kebalikan algoritma enkripsi AES. Algoritma deskripsi AES menggunakan transformasi invers semua transformasi dasar yang digunakan pada algooritma enkripsi AES[1].

Algoritma 2.1 Enkripsi AES

Input: P, K \{Teks Asli 16 bytes, kunci AES (128, 192, 256 bit)\}

Output: CT $\{$ Teks sandi 16 bytes $\}$

$(\mathrm{Nr}, \mathrm{w}) \leftarrow$ EkspansiKunci $(\mathrm{K})\{\mathrm{Nr}$ : Jumlah Ronde, w : larik bytes kunci ronde $\}$

$\mathrm{CT}=\mathrm{P}$

AddRoundKey(CT, w [0..3])

For $\mathrm{i}=1 \rightarrow \mathrm{Nr}$ do

SubBytes $(\mathrm{CT})$

ShiftRows(CT)

If $\mathrm{i} \neq \mathrm{Nr}$ then

$\operatorname{Mix} \operatorname{Columns}(\mathrm{CT})$

End if

End for [1]

AddRoundKey(CT), w[(i * 4)..(i * 4) + 3])

Algoritma 2.1 Deskripsi AES

Input: P, K \{Teks Asli 16 bytes, kunci AES (128, 192, 256 bit)\}

Output: CT $\{$ Teks sandi 16 bytes $\}$

$(\mathrm{Nr}, \mathrm{w}) \leftarrow$ EkspansiKunci $(\mathrm{K})\{\mathrm{Nr}$ : Jumlah Ronde, w : larik bytes kunci ronde $\}$

$\mathrm{P}=\mathrm{CT}$

AddRoundKey(P, w [(Nr*4)..(Nr*4) - 3]

For $\mathrm{i}=1 \rightarrow \mathrm{Nr}$ do

$\operatorname{InvSubBytes}(\mathrm{P})$

InvShiftRows $(\mathrm{P})$

AddRoundKey $(\mathrm{P}, \mathrm{w}[(\mathrm{Nr}-\mathrm{i}) * 4 . .((\mathrm{Nr}-\mathrm{i}) * 4)+3])$

If $\mathrm{i} \neq \mathrm{Nr}$ then

InvMixColumns $(\mathrm{P})$

End for[1]

End if 


\subsection{E-Commerce}

Ecommerce adalah proses berbisnis dengan memakai teknologi elektronik yang menghubungkan antara perusahaan, konsumen dan masyarakat dalam bentuk transaksi elektronik, dan pertukaran/penjualan barang, jasa, dan informasi secara eletronik[11].

Menurut Turban, Lee, King, Chung E-Commerce adalah proses jual beli atau pertukaran produk, jasa dan informasi melalui jaringan informasi termasuk internet[12]. Berdasarkan dari definisi diatas, dapat disimpulkan bahwa E-Commerce adalah penjualan dan pemasaran produk barang dan jasa menggunakan jaringan komunikasi termasuk internet untuk melakukan proses bisnis.

\section{ANALISA DAN PEMBAHASAN}

Pada penelitian ini, algoritma Advanced Encryption Standard (AES) diimplementasikan sebagai pengamanan form login dan data customer pada website e-commerce. Dalam proses login, ketika username dan password dimasukkan maka akan otomatis dienkripsi, setelah proses enkripsi berhasil dan data sesuai maka website dapat diakses. Untuk memulai proses enkripsi siapkan 2 buah array berukuran 4x4 bernama Plaintext dan Key.

Pilih Plaintext yang akan dienkripsi beserta kuncinya, pada contoh berikut memakai record password pada data customer :

Password (Plaintext): "helloapakabarnya"

Key : "kabarakubaiksaja"

Plaintext dan key tersebut dikonversikan ke dalam bentuk bit menggunakan kode ASCII. Lalu Konversikan kode ASCII tersebut ke dalam heksadesimal. Kemudian Masukkan tiap-tiap bagian teks tersebut ke dalam tiap-tiap sel pada matriks berukuran $4 \times 4$. Sehingga hasilnya sebagai berikut :

\begin{tabular}{|c|c|c|c|}
\hline \multicolumn{4}{|c|}{ Plaintext } \\
\hline 68 & 6f & $6 \mathrm{~b}$ & 72 \\
\hline 65 & 61 & 61 & $6 \mathrm{e}$ \\
\hline $6 c$ & 70 & 62 & 79 \\
\hline $6 c$ & 61 & 61 & 61 \\
\hline
\end{tabular}

\begin{tabular}{|c|c|c|c|}
\multicolumn{5}{c}{ Key } \\
\hline $6 \mathrm{~b}$ & 72 & 62 & 73 \\
\hline 61 & 61 & 61 & 61 \\
\hline 62 & $6 \mathrm{~b}$ & 69 & $6 \mathrm{a}$ \\
\hline 61 & 75 & $6 \mathrm{~b}$ & 61 \\
\hline
\end{tabular}

Sebelum melakukan langkah selanjutnya terlebih dahulu membuat key schedule yang di XOR kan dengan nilai yang ada pada table RCon, yang hasilnya disebut Roundkey pada ditahapan enkripsi. Setelah mendapatkan Roundkey 1-roundkey 10 maka dilakukan proses sebagai berikut :

1. Lakukan AddRoundKey (Initial State)

Pada proses ini key digabungkan dengan Plaintext. Proses penggabungan ini menggunakan operasi XOR untuk setiap byte dari key dengan setiap byte dari plaintext. Sehingga hasilnya sebagai berikut :

Tabel 1. Proses AddRoundKey

\begin{tabular}{|c|c|c|c|c|c|c|c|c|c|c|c|c|c|}
\hline 68 & $6 \mathrm{f}$ & $6 \mathrm{~b}$ & 72 & & $6 \mathrm{~b}$ & 72 & 62 & 73 & & 03 & $1 \mathrm{~d}$ & 09 & 01 \\
\hline 65 & 61 & 61 & $6 \mathrm{e}$ & $\triangle$ & 61 & 61 & 61 & 61 & & 04 & 00 & 00 & Of \\
\hline $6 c$ & 70 & 62 & 79 & $\oplus$ & 62 & $6 \mathrm{~b}$ & 69 & $6 a$ & $=$ & $0 \mathrm{e}$ & $1 b$ & $0 \mathrm{~b}$ & 13 \\
\hline $6 c$ & 61 & 61 & 61 & & 61 & 75 & $6 \mathrm{~b}$ & 61 & & $0 \mathrm{~d}$ & 14 & $0 \mathrm{a}$ & 00 \\
\hline
\end{tabular}

2. Lakukan langkah SubBytes

Proses SubBytes adalah operasi yang akan melakukan substitusi tidak linear dengan cara mengganti setiap byte dari initial state hasil langkah AddRoundKey (initial state) dengan byte pada sebuah tabel yang SBox. Misal, akan menggantikan elemen 03 pada initial state. Maka elemen yang bersesuaian pada SBox terletak pada baris ke-0 dan kolom ke-3 yaitu hasilnya $7 \mathrm{~b}$. Kemudian lakukan pada byte-byte selanjutnya. Hasilnya dapat dilihat pada berikut ini :

Tabel 2. Proses SubBytes

\begin{tabular}{|c|c|c|c|c|c|c|c|}
\hline \multicolumn{4}{|c|}{ Initial State } & \multicolumn{4}{|c|}{ SubBytes } \\
\hline 03 & $1 \mathrm{~d}$ & 09 & 01 & $7 \mathrm{~b}$ & $\mathrm{a} 4$ & 01 & $7 \mathrm{c}$ \\
\hline 04 & 00 & 00 & of & $\mathrm{f} 2$ & 63 & 63 & 76 \\
\hline $0 \mathrm{e}$ & $1 b$ & $0 \mathrm{~b}$ & 13 & $a b$ & af & $2 b$ & $7 \mathrm{~d}$ \\
\hline $0 \mathrm{~d}$ & 14 & $0 \mathrm{a}$ & 00 & $\mathrm{~d} 7$ & $\mathrm{fa}$ & 67 & 63 \\
\hline
\end{tabular}

3. Lakukan langkah Shift $\overline{\text { Rows }}$

Proses ShiftRows akan beroperasi pada tiap baris dari tabel plaintext. Proses ini akan bekerja dengan cara memutar bytebyte pada 3 baris terakhir (baris 1, 2, dan 3) dengan jumlah perputaran yang berbeda-beda. Baris 1 akan diputar sebanyak 1 kali, baris 2 akan diputar sebanyak 2 kali, dan baris 3 akan diputar sebanyak 3 kali. Sedangkan baris 0 tidak akan diputar. Hasilnya dapat dilihat sebagai berikut : 
Tabel 3. Proses ShiftRows

\begin{tabular}{|c|c|c|c|c|c|c|c|}
\hline $7 b$ & a4 & 01 & $7 \mathrm{c}$ & $7 b$ & $\mathrm{a} 4$ & 01 & $7 c$ \\
\hline $\mathrm{f} 2$ & 63 & 63 & 76 & 63 & 63 & 76 & $\mathrm{f} 2$ \\
\hline$a b$ & af & $2 b$ & $7 d$ & $2 b$ & $7 d$ & $a b$ & af \\
\hline $\mathrm{d} 7$ & fa & 67 & 63 & 63 & d7 & fa & 67 \\
\hline
\end{tabular}

4. Lakukan langkah MixColumns

Proses MixColumns dapat dilakukan dengan mengalikan koordinat vector dari empat nomor pada Rijndael's Galoisfield menggunakan operasi perkalian matriks dengan rumus dibawah ini :

$$
\left[\begin{array}{l}
r 0 \\
r 1 \\
r 2 \\
r 3
\end{array}\right]=\left[\begin{array}{llll}
2 & 3 & 1 & 1 \\
1 & 2 & 3 & 1 \\
1 & 1 & 2 & 3 \\
3 & 1 & 1 & 2
\end{array}\right]\left[\begin{array}{l}
a \\
a 1 \\
a 2 \\
a 3
\end{array}\right]
$$

Dimana r0, r1, r2 dan r3 adalah hasil setelah transformasi. a0 - a3 dapat diperoleh dari matriks setelah data mengalami proses substitusi dalam Sbox. Untuk memperoleh nilai r0, rumusnya seperti dibawah ini :

$$
\begin{aligned}
& r 0=\{02 . a 0\} \text { xor }\{03 . a 1\} \text { xor }\{01.02\} \text { xor }\{01.03\} \\
& r 1=\{01 . a 0\} \text { xor }\{02 . a 1\} \text { xor }\{03.02\} \text { xor }\{01.03\} \\
& r 2=\{01 . a 0\} \text { xor }\{01 . a 1\} \text { xor }\{02.02\} \text { xor }\{03.03\} \\
& r 3=\{03 . a 0\} \text { xor }\{01 . a 1\} \text { xor }\{01.02\} \text { xor }\{03.03\}
\end{aligned}
$$

Tabel 4. Hasil MixColumns

\begin{tabular}{cccc}
\hline $1 \mathrm{~b}$ & $5 \mathrm{c}$ & $\mathrm{c} 9$ & $3 \mathrm{~d}$ \\
\hline $\mathrm{a} 3$ & 32 & $\mathrm{f} 1$ & $0 \mathrm{e}$ \\
$\mathrm{ab}$ & $5 \mathrm{f}$ & $2 \mathrm{f}$ & 62 \\
03 & $5 \mathrm{c}$ & 31 & 17 \\
\hline
\end{tabular}

\begin{tabular}{|c|c|c|c|c|c|c|c|c|c|c|c|c|c|}
\hline $1 b$ & $5 c$ & c9 & $3 d$ & \multirow{3}{*}{$\bigoplus$} & 85 & f7 & 95 & e6 & \multirow[b]{3}{*}{$=$} & $9 \mathrm{e}$ & $a b$ & $5 c$ & $\mathrm{db}$ \\
\hline a3 & 32 & $\mathrm{f1}$ & $\mathrm{Oe}$ & & 63 & 02 & 63 & 02 & & $\mathrm{cO}$ & 30 & 92 & Oc \\
\hline $\mathrm{eb}$ & $5 f$ & $2 f$ & 62 & & $8 d$ & e6 & $8 f$ & e5 & & 66 & b9 & $\mathrm{a} 0$ & 87 \\
\hline 03 & $5 c$ & 31 & 17 & & ee & $9 b$ & fo & 91 & & ed & c7 & $\mathrm{c} 1$ & 86 \\
\hline
\end{tabular}

5. Lakukan langkah AddRoundKey (Round 1)

Pada proses ini key digabungkan dengan plaintext (hasil dari perhitungan MixColumns). Key pada proses AddRoundKey ini berbeda dengan AddRoundKey pada langkah 4 yaitu menggunakan key schedule (round 1) yang telah dibuat sebelumnya yaitu pada langkah 3. Untuk proses penggabungannya sama seperti pada langkah 4 sebagai berikut :

Ulangi kembali langkah SubBytes, ShiftRows, MixColumns, dan Addroundkey sebanyak 9 kali untuk mendapatkan hasil round 2 sampai round 9. Sedangkan untuk mendapatkan hasil untuk round 10 ulangi langkah SubBytes, ShiftRows, dan Addroundkey (final state). Ciphertext yang dihasilkan dari langkah-langkah enkripsi algoritma AES dapat dilihat sebagai berikut :

\begin{tabular}{|c|c|c|c|c|c|c|c|}
\hline 05 & $\mathrm{Fd}$ & $3 b$ & 66 & 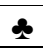 & ý & ; & $\mathrm{f}$ \\
\hline $7 b$ & $\mathrm{Fa}$ & $\mathrm{a} 5$ & ed & \{ & ú & $¥$ & 1 \\
\hline 98 & Ac & 28 & $\mathrm{~d} 7$ & $\sim$ & $\neg$ & ( & $x$ \\
\hline 40 & $5 \mathrm{e}$ & $0 \mathrm{c}$ & f7 & @ & $\wedge$ & q & $\div$ \\
\hline
\end{tabular}

Tabel 5. Ciphertext

\begin{tabular}{llll}
\hline 05 & fd & $3 \mathrm{~b}$ & 66 \\
\hline $7 \mathrm{~b}$ & fa & a5 & ed \\
98 & ac & 28 & d7 \\
40 & $5 \mathrm{e}$ & $0 \mathrm{c}$ & $\mathrm{f7}$ \\
\hline
\end{tabular}

Setelah hasil enkripsi diperoleh, maka selanjutnya hasil tersebut dikonversikan kembali kedalam bentuk teks berdasarkan tabel ASCII. Hasil konversinya dapat dilihat sebagai berikut :

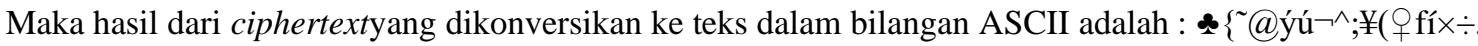

\section{IMPLEMENTASI}


Pada tahapan implementasi dilakukannya penerapan program yang sudah dirancang terhadap suatu sistem. Pada tahapan ini beberapa perangkat yang dibutuhkan berupa perangkat keras dan perangkat lunak agar program dalam diterapkan dan berjalan dengan baik. Berikut perangkat yang diperlukan :

1. Perangkat Keras

Perangkat keras yang dapat digunakan merupakan perangkat yang pada umumnya biasa digunakan, yaitu :

a. Prosessor intel Core 2 Duo $2 \mathrm{GHz}$ (T6400)

b. Memori 2 GB DDRII

c. Harddisk 320 GB SATA

d. Keyboard dan Mouse standar komputer

2. Perangkat Lunak

Perangkat lunak yang dibutuhkan untuk menjalankan program, yaitu :

a. Sistem Operasi Windows 732 bit

b. Xampp Control Panel v3.2.2

c. Browser Internet (Mozila Firefox, Chrom, dll)

Tampilan program merupakan hasil tampilan dari program yang sudah dirancang selanjutnya akan diteruskan pada tahapan implementasi sistem, yang digunakan untuk memperjelas tampilan-tampilan yang ada pada program website $e$ commerce. Pada tahapan ini akan menjelaskan fungsi dari setiap tampilan yang dihasilkan.

Pada form login ini berfungsi untuk memberikan verifikasi hak akses terhadap user admin, sehingga admin yang mengakses memiliki wewenang sesuai dengan privasi usename dan password yang dimiliki. Gambar hasil dari form login sebagai berikut :

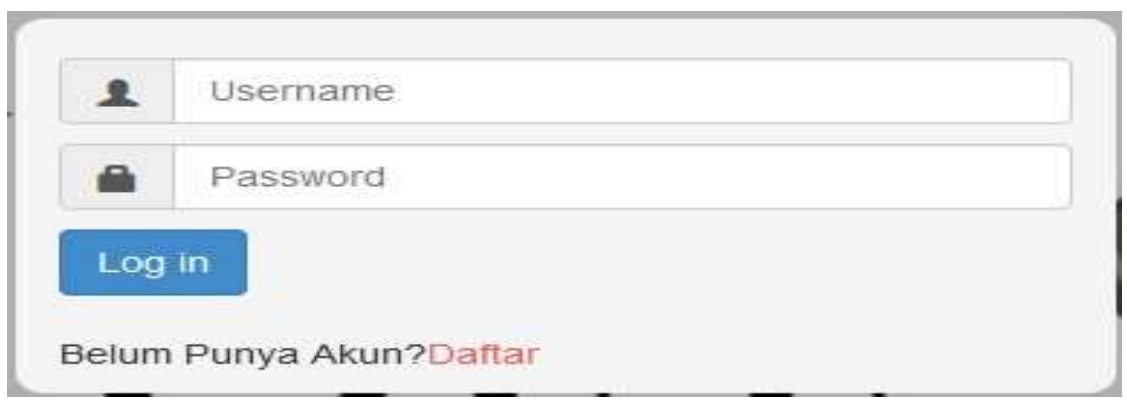

Gambar 1. Tampilan form login

Pada tampilan ini berfungsi untuk membuat akun baru untuk customer pada website e-commerce sehingga customer yang baru bergabung dan membuat akun dapat berbelanja dengan data yang sudah didaftarkan. Gambar hasil dari from daftar sebagai berikut :

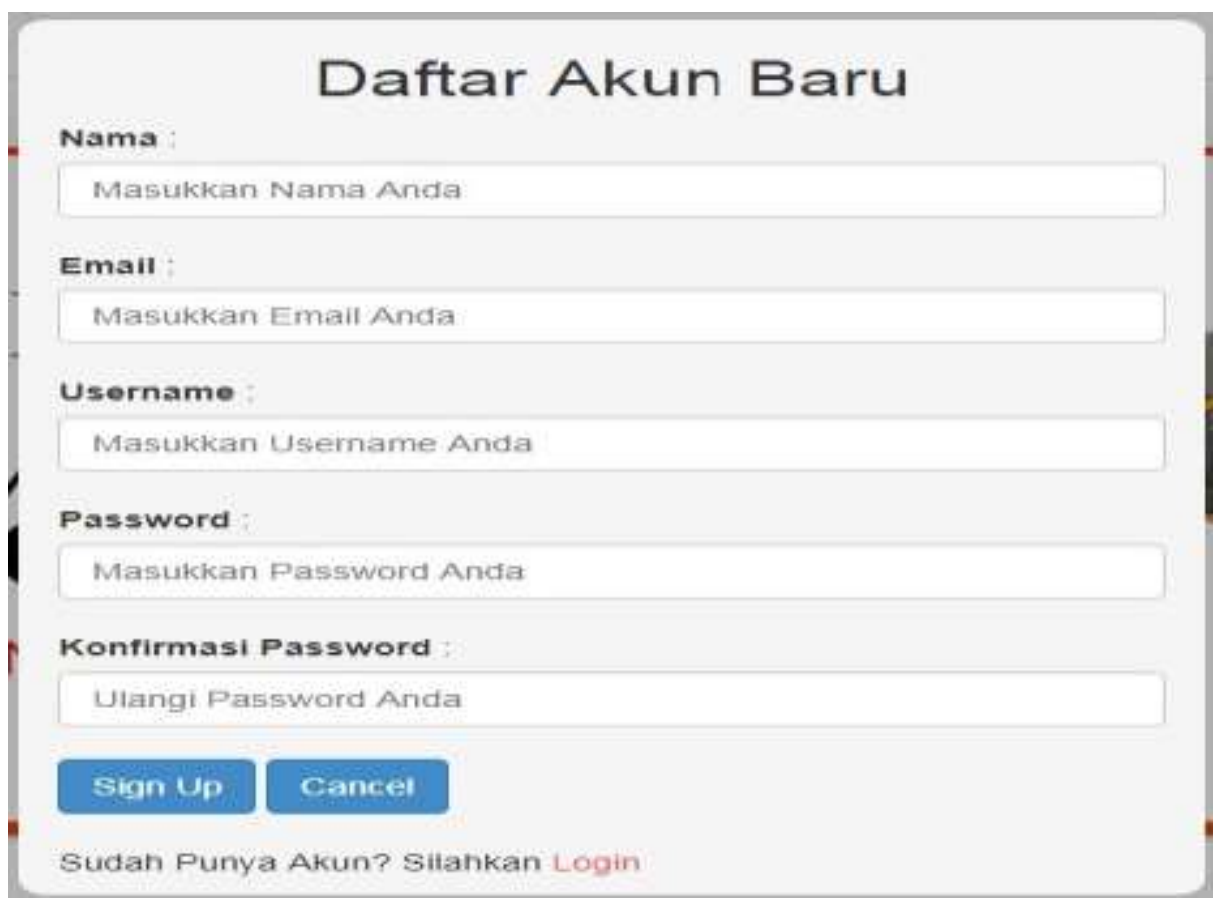

Gambar 2. Tampilan form daftar

Tampilan menu utama merupakan tampilan pertama ditampilkan pada awal website e-commerce. Dalam menu utama terdapat pilihan sub menu seperti beranda, produk, tentang kami, kontak, login/logout untuk customer dan keranjang belanja yang dapat dipilih untuk melakukan perintah selanjutnya. Gambar hasil dari menu utama sebagai berikut : 


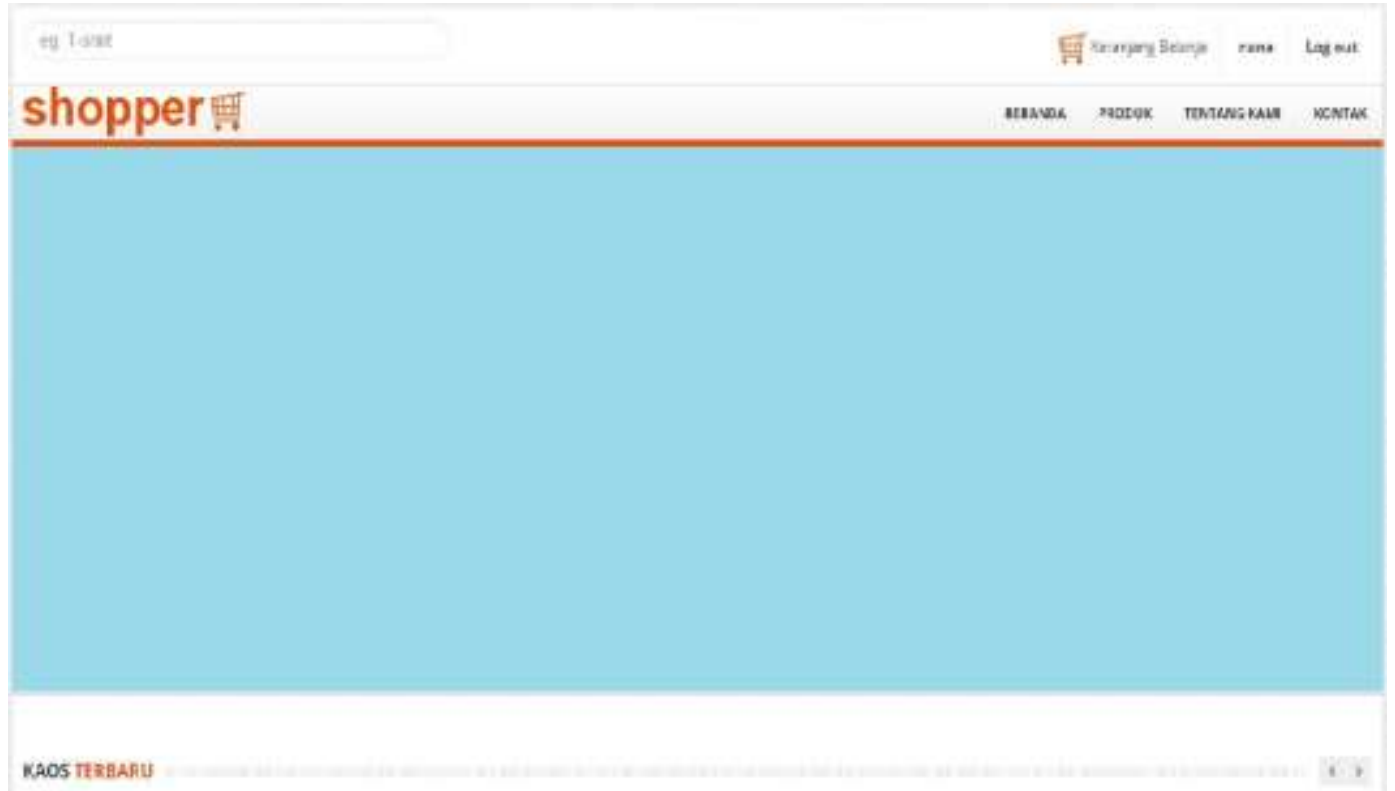

Gambar 3. Tampilan menu utama

Pada tampilan menu produk merupakan tampilan dari beberapa gambar produk seperti baju atau kaos beserta harga dan deskripsinya. Mana opsi menu produk dapat dipilih kategori produk yang ingin dibeli. Gambar hasil dari menu produk sebagai berikut :

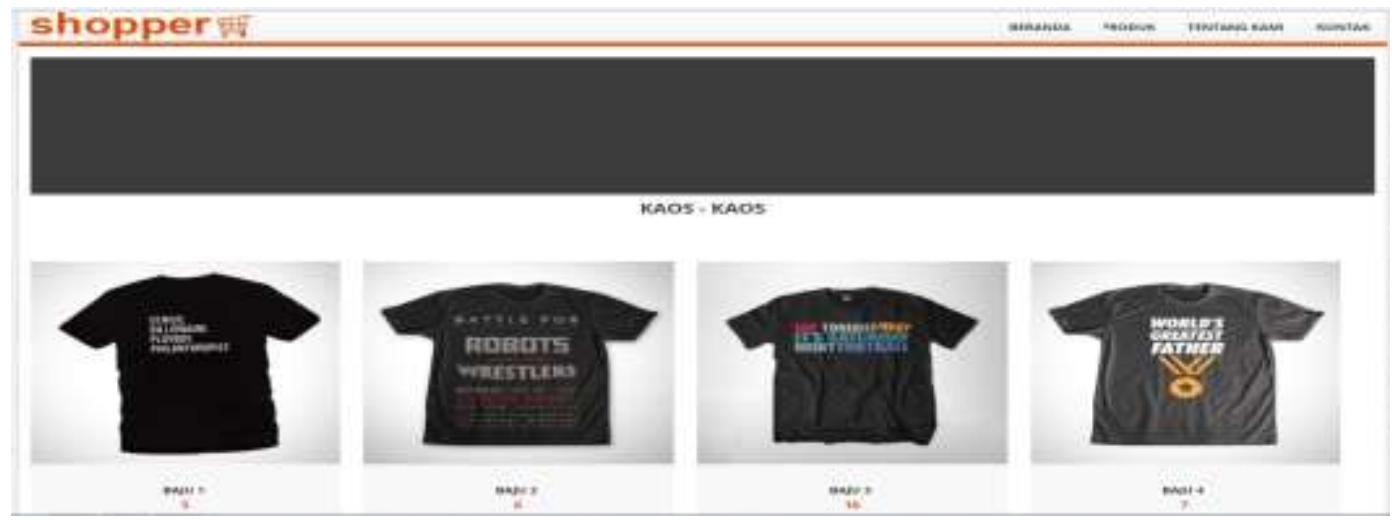

Gambar 4. Tampilan menu produk

Pada tampilan halaman admin merupakan tampilan yang hanya dapat diakses oleh admin dan user yang berhak mengakses halaman. Dalam halaman admin dapat pilihan perintah selanjutnya seperti dashboard, user, barang, pesan, pembeli, tentang kami, dan kontak. Gambar hasil tampilan halaman admin sebagai barikut :

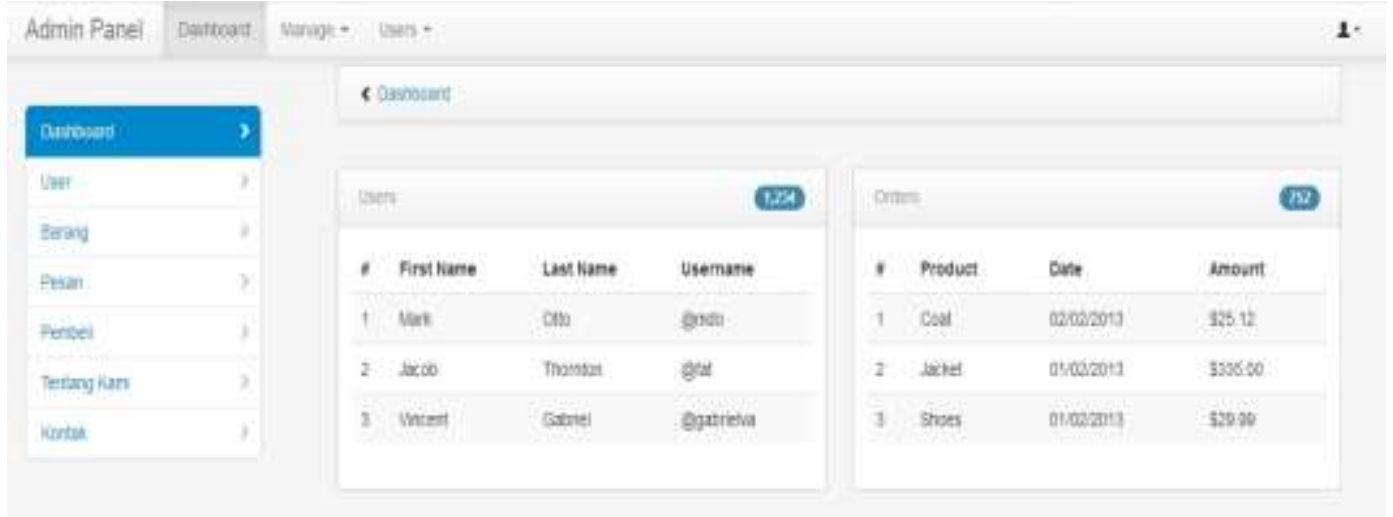

Gambar 5. Tampilan halaman admin

Pada tampilan data user merupakan tampilan dari daftar user berupa username dan password yang sudah dilakukan pengamanan enkripsi pada password user. Gambar hasil tampilan data user sebagai berikut : 


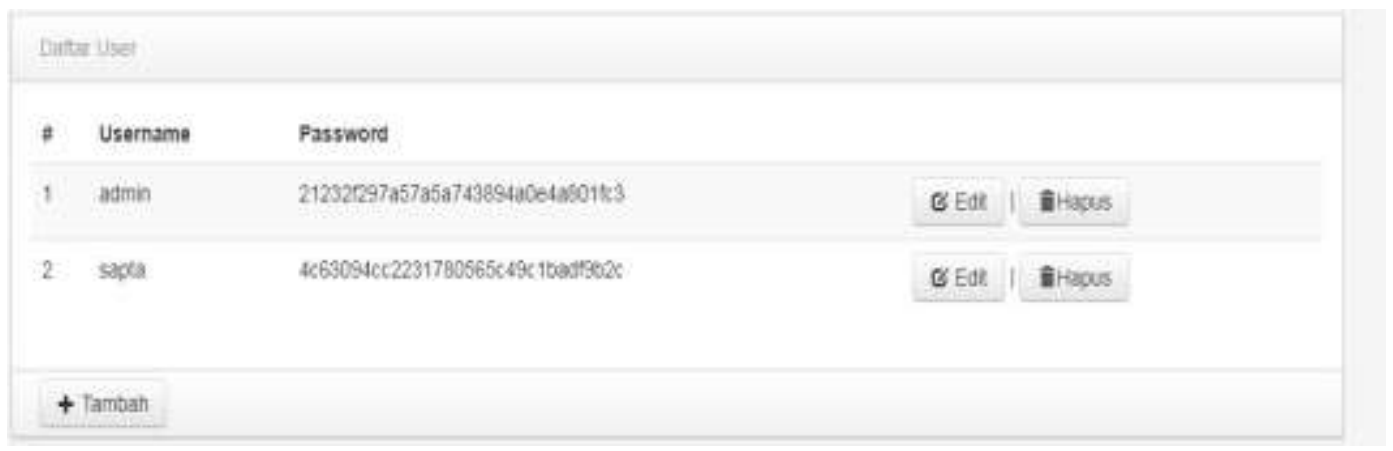

Gambar 6. Tampilan data user

Pada tampilan data customer merupakan tampilan dari daftar customer yang telah mendaftar data pribadinya ke website e-commerce berupa nama, email, alamat, no hp, dll. Gambar hasil tampilan data customer sebagai berikut :

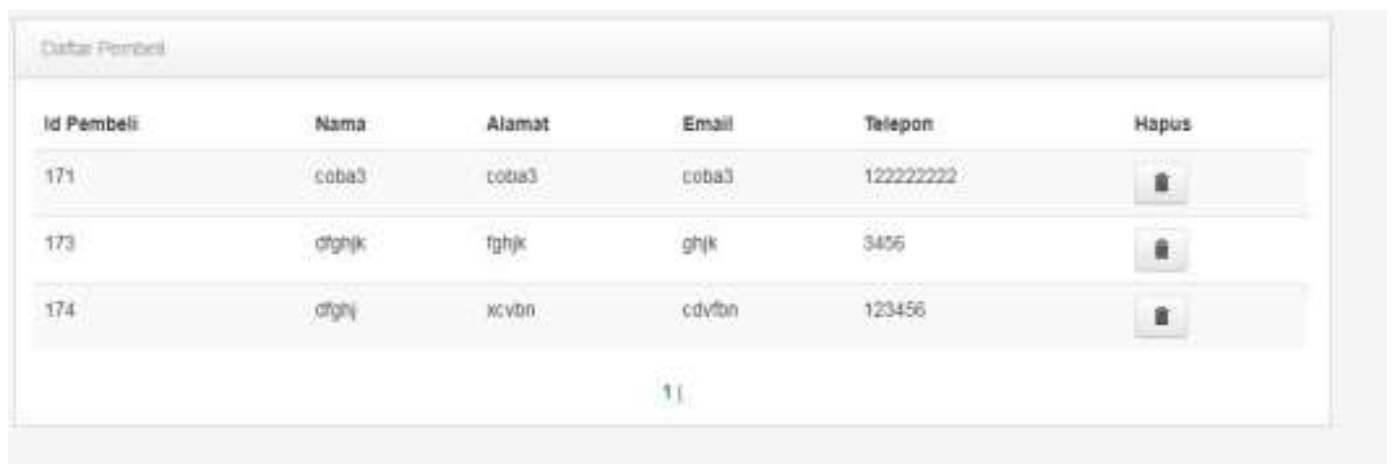

Gambar 7. Tampilan data customer

Pengujian sistem merupakan proses tes program, apakah telah sesuai dengan rancangan sebelumnya, sehingga program ini dapat digunakan sebagaimana mestinya, yaitu :

1. Menjalankan program untuk mengetahui hasil perancangan program telah sesuai output dari tujuan perancangan. Program berhasil dijalankan dan hasil telah sesuai dengan perancangan.

2. Melakukan login dengan memasukkan usename dan password. Password login telah otomatis di enkripsi menggunakan algoritma AES dan berhasil.

\section{KESIMPULAN}

Berdasarkan hasil pembahasan dan uji coba yang telah dilakukan, dapat disimpulkan sebagai berikut :

1. Dengan implementasi algoritma AES pada website e-commerce ini dapat memberikan keamanan pada saat login dan keamanan data customer

2. Pemilihan algoritma AES dirasa tepat karena algoritma ini cukup sulit dipecahkan, dan dalam pengoperasiannya memori yang terpakai tidak besar.

3. Panjang kunci akan mempengaruhi lamanya proses enkripsi dan deskripsi, juga mempengaruhi tingkat keamanannya.

4. Dengan penggunaan panjang kunci 128 bit proses yang dilakukan lebih cepat karena hanya melakukan perputaran sebanyak 10 round.

5. Perancangan dibuat menggunakan bahasa pemograman PHP dan database MySQL.

\section{REFERENCES}

[1] R. Sadikin, Kriptogafi Untuk Keamanan Jaringan, Yogyakarta: Andi. 2012

[2] S. Anwar, "Implementasi Pengamanan Data Dan Informasi Dengan Metode Steganografi LSB Dan Algoritma Kriptografi AES," vol. 6, pp. 65-74, 2017

[3] S. M. Maulana, H. Susilo, and Riyadi, "Implementasi E-Commerce Sebagai Media Penjualan Online,” J. Adm. Bisnis( JAB), vol. 29, no. 1, pp. 1-9, 2015

[4] D. Ariyus, Pengantar Ilmu Kriptografi Teori, Analisis dan Implementasi, Yogyakarta: Andi. 2008

[5] Kusrini \& Koniyo. Andry, Tutunan Praktis Membangun Sistem Informasi Akutansi dengan Visual Basic dan Microsoft SQL Server, Andi. 2007

[6] G. B. Davis, Manajemen Sistem Informasi, Jakarta: PT Gramedia Pustaka Utama. 2005

[7] Gordon B. Davis, Kerangka Dasar Sistem Informasi Manajemen Bagian 1 PT Pustaka Binamas Pressindo, Jakarta: Pustaka Binaman Pressindo. 1991

[8] H. I. Yunarto and M. G. Santika, Business Concepts Implementation Series in Inventory Management, Elex Media Komputindo. 2005

[9] P. Kotler and Keller, Manajemen Pemasaran, Prenhallindo. 2007

[10] P. Procter, Cambridge International Dictionary of English, Cambridge University Press. 1995

[11] Suwardi, Hukum Dagang Suatu Pengantar, Deepublish. 2015

[12] Suyanto, Top, Strategi Periklanan pada E-Commerce Perusahaan Dunia, Yogyakarta: Andi. 2003

[13] Yuhefizar, CMM Website Interaktif MCMS Joomla(CMS), Jakarta: Elex Media Komputindo. 2009 
JURIKOM (Jurnal Riset Komputer), Vol. 7 No. 1, Februari 2020 e-ISSN 2715-7393 (Media Online), p-ISSN 2407-389X (Media Cetak)

DOI 10.30865/jurikom.v7i1.1943

[14] L. Hakim, Cara Cerdas Menguasai Layout, Desain, dan Aplikasi Web, Jakarta: Elex Media Komputindo. 2004

[15] Anhar, Panduan mengusai PHP dan MySQL secara Otodidak, Jakarta: Mediakita. 2010

[16] Supono and V. Putratama, Pemrograman Web dengan Menggunakan PHP dan Framework Codeigniter. 2016

[17] M. R. Arif, Pemrograman Basis Data Menggunakan Transact-SQL dengan Microsoft SQL Server, Andi. 2006

[18] B. K. Miftakhul Huda, Membuat Aplikasi Database, Elex Media Komputindo. 2010

[19] D. M. Kroenke, Database Processing Jilid 1, Erlangga. 2005

[20] M. Indrajani, S.Kom., Database Design - Case Study All In One, Elex Media Komputindo. 2015

[21] A. Haromainy, Aplikasi Most Wanted Untuk Media USB, Jakarta: Elex Media Komputindo. 2010 